\title{
Gender and healthcare accessibility in Europe
}

\author{
Maria da Conceição Constantino Portela ${ }^{1}$, Adalberto Campos Fernandes ${ }^{2}$ \\ 1. Health Sciences Institute, The Catholic University of Portugal, Palma de Cima, Lisbon, Portugal. 2. National School of \\ Public Health, New University of Lisbon, Avenida Padre Cruz, Lisbon, Portugal. \\ Correspondence: Maria da Conceição Constantino Portela. Address: Health Sciences Institute, The Catholic University of \\ Portugal. Palma de Cima, Lisbon, Portugal. E-mail: mccportela@gmail.com
}

Received: August 14, 2014

Accepted: October 26, 2014

Online Published: November 5, 2014

DOI : $10.5430 /$ jha.v3n6p163

URL: http://dx.doi.org/10.5430/jha.v3n6p163

\section{Abstract}

Objective: Healthcare accessibility is necessary to achieve good health outcomes. However, access to healthcare can be decreased due to distance to healthcare centres, high costs, or waiting lists. The present study explored if there is a gender gap related to healthcare accessibility constraints.

Methods: We performed a cross-country transversal study to investigate the existence of gender-related healthcare accessibility constraints using Mann-Whitney $U$ tests. The research was based on self-reported unmet needs for medical examination due to access barriers according to Eurostat. We examined annual observations from 2005 through 2011 from eight European countries: Greece, France, Germany, Ireland, Italy, Portugal, Spain, and the United Kingdom.

Conclusions: We found a gender gap related to unmet medical needs due to high costs, with females more likely to have such needs. The difference in mean values related to gender was statistically significant for Greece $(5.17 \%$ vs. $3.59 \%$; $p=.007)$, France (1.80\% vs. 1.23\%; $p=.007)$, Ireland (1.53\% vs. 1.13\%; $p=.011)$, and Italy (4.39\% vs. $2.99 \% ; p=.004)$.

\section{Key words}

Healthcare system, Accessibility, Gender, Austerity, Cost, Waiting lists

\section{Introduction}

Accessibility to healthcare is usually concerned with health system coverage and focuses mainly on eligibility criteria for coverage ${ }^{[1]}$, although it is "often perceived as being predominantly an attribute of services and is determined by factors such as the availability, price, and quality of health resources, goods, and services” ${ }^{[2]}$. Nonetheless, it can also be considered as a function of both supply and demand, according to Mooney as cited by Levesque et al. ${ }^{[2]}$.

In fact, "accessibility's strongest suit, is (...) how they are perceived and effectively utilized by individuals in the population with differing characteristics" ${ }^{[3]}$. There are political, economic, educational ${ }^{[4]}$ and epidemiological gender gaps, and it is logical to consider that such a gap might also exist for healthcare accessibility. The literature reports that males and females differ with regard to health, access to healthcare, and use of health services ${ }^{[5]}$, and these factors might also vary among countries with different healthcare system models.

There is a general consensus that there are three main categories of healthcare systems: a National Health Service model, a social insurance model, and a private insurance model ${ }^{[6]}$. Greece, Ireland, Italy, Portugal, the United Kingdom, and Spain 
belong to the first group, but France and Germany have social insurance models (see Table 1). All of them are universal systems, so everyone should be eligible and have access to the system. However, "only recently have typologies with a focus on patients and in particular on patient's access to healthcare emerged (...) putting access at the centre of a health typology strengthens a patient's perspective and thereby the impact of health services on individual health" ${ }^{[6]}$. A number of variables related to supply affect accessibility, such as the numbers of physicians and medical consultations. Table 1 shows that among the eight European countries mentioned above, Greece and Ireland have the most and fewest physicians, respectively. France and Germany have social insurance healthcare models and have the highest number of medical consultations; in these countries each individual physician had to perform more consultations compared to those in countries with national healthcare systems (except Spain).

Table 1. Healthcare system model, number of physicians per 1,000 inhabitants, and number of consultations with a medical doctor per inhabitant per year for eight European countries from 2005 to 2011

\begin{tabular}{|c|c|c|c|c|c|}
\hline \multirow{2}{*}{ Country } & \multirow{2}{*}{$\begin{array}{l}\text { Model of healthcare } \\
\text { system }\end{array}$} & \multicolumn{2}{|c|}{$\begin{array}{l}\text { Number of physicians per } 1,000 \\
\text { inhabitants }\end{array}$} & \multicolumn{2}{|c|}{$\begin{array}{l}\text { Number of consultations by a } \\
\text { medical doctor per inhabitant }\end{array}$} \\
\hline & & $\begin{array}{l}\text { Mean value and standard } \\
\text { deviation }\end{array}$ & $\mathbf{N}$ & $\begin{array}{l}\text { Mean value and } \\
\text { standard deviation }\end{array}$ & $\mathbf{N}$ \\
\hline France & Social insurance model & $3.31 \pm 0.03$ & 7 & $6.79 \pm 0.11$ & 7 \\
\hline Germany & Social insurance model & $3.92 \pm 0.16$ & 7 & $8.79 \pm 0.82$ & 7 \\
\hline Greece & National health system & $5.80 \pm 0.49$ & 7 & $3.95 \pm 0.01$ & 2 \\
\hline Ireland & National health system & $2.96 \pm 0.19$ & 6 & $3.54 \pm 0.37$ & 2 \\
\hline Italy & National health system & $3.98 \pm 0.18$ & 7 & 6.10 & 1 \\
\hline Portugal & National health system & $3.64 \pm 0.23$ & 7 & $4.11 \pm 0.20$ & 7 \\
\hline Spain & National health system & $3.90 \pm 0.11$ & 7 & $7.65 \pm 0.39$ & 3 \\
\hline United Kingdom & National health system & $3.81 \pm 0.21$ & 7 & $5.20 \pm 0.39$ & 5 \\
\hline
\end{tabular}

Note. Source: Calculations by the authors based on Eurostat data for the number of consultations per inhabitant and based on OECD data for the number of physicians per 1,000 inhabitants considering professionally active physicians for France, Germany, Greece, Ireland, Italy, and Spain and the number of physicians licensed to practice for Portugal and United Kingdom due to a lack of available data.

Nonetheless, given the universality of healthcare systems that we considered in our sample, we must highlight that universal coverage does not necessarily guarantee access equity, which is affected by changing economic and demographic conditions ${ }^{[7]}$. One study controlled for the effects of political and economic determinants found that in the absence of austerity and International Monetary Fund intervention, the probability of austerity in the field of healthcare is $15 \%$, which increases to 53\% in the presence of austerity but the absence of the International Monetary Fund adjustment programme (as is the case for Spain, France, and Italy), and to $79 \%$ in the presence of austerity and the International Monetary Fund adjustment programme (as is the case for Portugal, Ireland, and Greece) ${ }^{[8]}$.

The impact of austerity also stems from the funding mechanism; it is likely that social insurance-based healthcare is less susceptible to austerity policies and tax revenue fluctuations than tax-financed healthcare systems, although social insurance systems did appear more susceptible to declines in GDP per capita ${ }^{[8]}$.

According to previous research, "wealthier countries are associated with a weaker primary care structure and lower primary care accessibility, while Eastern European countries seemed to have used their growth in national income to strengthen the accessibility and continuity of primary care (...), and countries with a social-security based system are associated with lower levels of accessibility" ${ }^{[9]}$. However, the authors consider that "it is unknown why primary care in some countries is more accessible, provides better quality of care, and offers a broader scope of healthcare services compared to others" ${ }^{[9]}$. To overcome limiting factors regarding healthcare accessibility, universal healthcare systems tend to protect some parts of the population with exemption schemes or different co-payment plans. However we did not identify any gender-dependent examples. 
Healthcare accessibility may be related to gender, as female social tasks are more related to family than male tasks because women are perceived to possess more communal traits such as selflessness and concern for others compared to men ${ }^{[10]}$. Moreover, given their family roles, they might be less willing to travel during working hours. The published data also point out that an acute problem may emerge in single-parent families ${ }^{[11]}$. Wage gaps tend to result in higher earnings for males, who experience a less pronounced impact on healthcare expenditure compared with females. According to research data, household resource allocation follows the principle of the market value hypothesis in developing countries, and the resources tend to be allocated to family members whose labour obtains higher expected returns. Consistent with this hypothesis, researchers have found that female family members were in an inferior economic position ${ }^{[12]}$. Nevertheless, the results of an investigation based on data from the World Health Organization for the year 2002 did not identify gender differences in accessibility, targeting diseases of an acute or chronic nature ${ }^{[4]}$, or prophylactic or therapeutic care. Indeed the same pattern has been observed elsewhere: while women had greater familial responsibilities than men, they were not a barrier to the access or use of healthcare services ${ }^{[13]}$. The same conclusion was reached in a study on antiretrovirals; after adjusting for clinical characteristics, the female gender was independently associated with a lower likelihood of being 95\% adherent to antiretroviral therapy ${ }^{[14]}$.

A study in the United States examined the association of general and veteran-specific barriers of access to healthcare among female veterans and found that $19 \%$ had a delayed or unmet healthcare need (...) ${ }^{[15]}$. Among those individuals delaying or going without care, the barriers varied by age group and included unaffordable healthcare (63\% of 18-34 years old group versus $12 \%$ in the 65 -plus age group), inability to take off from work ( $3 \%$ of those $<50$ years old), and transportation difficulties (36\% of the 65-plus group) ${ }^{[15]}$.

Accessibility can be assessed by determining if individual health needs are attained ${ }^{[16]}$; however, this concept is not straightforward, as “some cultures tend to amplify patients' perceptions of needs, while others downplay the immediacy of needs" ${ }^{[17]}$. The same perception is observed within countries ${ }^{[18]}$. In the present study, we considered self-reported unmet medical needs as defined by Eurostat: a "person's own assessment of whether he or she needed examination or treatment for a specific type of healthcare, but didn't have it or didn’t seek it” ${ }^{\text {[19] }}$.

Cost can be a barrier related to accessibility, as it puts pressure on a household budget, and greater healthcare needs result in greater cost. The unemployment rate is an important variable to consider because it is associated with lower income. When there is an increase in the unemployment rate, there is a higher probability of individuals forgoing healthcare. Moreover, "the experienced cost barriers not only affect the use of healthcare but also people's trust in the system" [20]. According to Table 2, the highest unemployment rates were found for females in Spain and Greece during the 7-year study period.

Table 2. Mean values of unemployment rates for males and females for the eight European countries from 2005 to 2011

\begin{tabular}{lll}
\hline \multirow{2}{*}{ Country } & \multicolumn{2}{c}{ Unemployment rate (\%) Mean value and standard deviation } \\
\cline { 2 - 3 } & Female & Male \\
\hline France & $9.70 \pm 0.72$ & $8.53 \pm 0.77$ \\
Germany & $8.17 \pm 1.94$ & $8.53 \pm 1.85$ \\
Greece & $14.84 \pm 3.30$ & $7.69 \pm 3.62$ \\
Ireland & $6.64 \pm 2.91$ & $10.26 \pm 6.11$ \\
Italy & $9.13 \pm 0.77$ & $6.29 \pm 1.08$ \\
Portugal & $10.50 \pm 1.61$ & $9.59 \pm 2.09$ \\
Spain & $15.54 \pm 4.69$ & $12.64 \pm 6.65$ \\
United Kingdom & $5.69 \pm 1.13$ & $6.94 \pm 1.60$ \\
\hline
\end{tabular}

Note. Source: Calculations by the authors based on 2013 EUROSTAT data. 
A study of oncology patients in the United States identified several cost categories affected by price: the prevalence of forgoing care due to cost among cancer survivors was $7.8 \%$ for medical care, $9.9 \%$ for prescription medications, $11.3 \%$ for dental care, and $2.7 \%$ for mental healthcare ${ }^{[21]}$. Usually the costs associated with healthcare did not reflect their actual price, as they were presented as user fees to limit unnecessary access. However, they are barriers when they compromise access to necessary care.

The impact associated with health insurance should be considered as it can be related to gender and is able to reflect the differential healthcare use. Indeed, employment-related factors (specifically, full-time work) tend to increase the likelihood of coverage for women but not for men after controlling for other variables, indicating that women are more likely than men to be insured through employer-based programmes ${ }^{[5]}$. Following the pilot programme in the state of Massachusetts, research data show that existence of mandatory health insurance is associated with a $4.8 \%$ lower probability of forgoing care because of cost ${ }^{[22]}$. Conversely, "in countries where payment is not required to access secondary healthcare, waiting time can be a barrier to access” ${ }^{[23]}$.

Another variable is distance to healthcare centres, which may have different accessibility implications, especially if it is related to single or multiple contacts. A single contact would be less affected by this variable, but accessibility is expected to be reduced when individuals require multiple visits to a centre that is far away. As acute episodes tend to be extremely serious and possibly life-threatening ones, distance should be evaluated in terms of mobilisation of healthcare systemrelated resources rather than private resources.

In contrast, among individuals with chronic conditions, healthcare centre visits are usually for monitoring or therapeutic interventions. In this situation, distance constraints tend to be more relevant due to repeated contacts with the healthcare system and the use of personal travel resources.

Mobility must also be considered as it can constrain autonomy. This can be due to multiple factors including an underlying disease, age, and employment status. With regard to underlying disease, musculoskeletal system disorders are common in older subjects and tend to limit mobility. Considering the latter, the need to leave work to visit a healthcare centre can strain employee-employer relationships.

This variable can also be highlighted from the perspective of health system organisation. Incidentally, research in two South American countries concluded that individual factors that discourage people from seeking healthcare appear to be less important than those related to health system design and organisation, including shortfalls in infrastructure, service organisation and quality, and problems with enrolment ${ }^{[24]}$.

Some researchers have found that the effect of travel time is significantly reduced after adjusting for small-scale measures of socio-economic deprivation ${ }^{[25]}$. This highlights the importance of a socio-economic basis for healthcare system planning. Nonetheless, individual interpretations of healthcare needs related to distance ${ }^{[3]}$ remain at the core of decisions to travel.

We previously studied variables related to healthcare demand; here we focus on supply. Waiting lists increase in length when there is a mismatch between healthcare demand and supply ${ }^{[17]}$, with a surplus in demand and/or a deficit in supply. Which means they are perceived to ration imperfectly ${ }^{[18]}$.

Waiting lists are heterogeneous. Emergency cases are dealt with immediately. However, an intervention to treat a chronic condition can be postponed until adverse event occurrence or disease exacerbation. However, when considering acute and severe episodes, waiting lists are not acceptable as they impose a new burden on an already sick patient. The difference between waiting lists and waiting times should be considered, as "it is the length of the wait that is important to patients, as a long list may not necessarily mean a long wait if patients are processed quickly, although there is likely to be a correlation between the two" ${ }^{\text {[16] }}$. 
These patients can be identified either at a hospital or primary care facility; however, their management is different according to each one of these settings. Considering the former, it is preferential to improve supply, including the availability of beds, staff, and funds ${ }^{[16]}$, possibly by appealing to the private sector. The opposite should be taken into account regarding the latter (public funds for private ventures). Here, the demand can be managed mainly by imposing additional barriers ${ }^{[17]}$ such as taxes or gatekeeping.

Whatever the context, equity must be preserved. This means that interventions to rationalise the healthcare system must ensure that necessary care will not be postponed.

\section{Methodology}

This research aimed to investigate whether there is a gender gap in healthcare accessibility due to distance, cost, or waiting list length in eight European countries over a 7-year period (2005 to 2011).

We collected data on the percentages of patients with self-reported unmet medical needs regarding all types of healthcare in eight European countries. The sample considers the individuals at country level, regarding all age groups, education levels, and labour and income statuses.

The accessibility constraints were considered in three areas for each gender: distance to the healthcare centre, cost, and waiting lists. We also assessed unemployment rates to have economic information at the country level.

We included data from eight European countries: Spain, Italy, France, Portugal, Greece, Ireland, the United Kingdom, and Germany. The first three had an austerity period with severe financial impacts, the next three experienced this and international bailouts, and the United Kingdom and Germany experienced neither.

The data were obtained from the Eurostat database. It considers a 7-year period from 2005 to 2011. There are 56 observations for each of the three variables related to accessibility and regarding each gender.

Non-parametric statistical analyses were carried out to identify potential gender-related differences among unmet medical needs due to cost, distance, or waiting lists. Considering the number of cases, the differences in mean values regarding the percentage of patients with unmet medical needs were analysed with Mann-Whitney $U$ tests. A $p$ value $<.05$ was considered statistically significant.

\section{Results}

Considering the number of observations in the sample ( $n=333$ ), we found that from 2005 until 2011, the mean percentage of patients with unmet medical needs due to cost, waiting lists, and distance was higher for females than for males. The highest value of $2.53 \%$ was for female patients with unmet medical needs due to expensive healthcare, whereas this value was just $1.80 \%$ for males. Overall, $0.79 \%$ of females reported unmet medical needs due to waiting lists compared to $0.66 \%$ in males. Distance was associated with the lowest values of unmet medical needs for both genders.

\subsection{Effects related to unmet medical needs due to long distance}

We found that during the sample time horizon just $0.14 \%$ and $0.08 \%$ of females and males, respectively, described healthcare accessibility constraints due to distance. There was a huge decrease until 2007, at which point the mean value remained stable for females until 2008; only by 2010 it started another decrease. For males, the value increased from 2007 to 2009 when dropped suddenly and increases 2010 afterwards. It seems that by 2011 there was a convergent trend (see Figure 1). 
Figure 1. Percentages of male and female patients who reported unmet medical needs due to distance in eight European countries from 2005 to 2011.

Note. Source: Calculations by the authors based on 2013 EUROSTAT data.

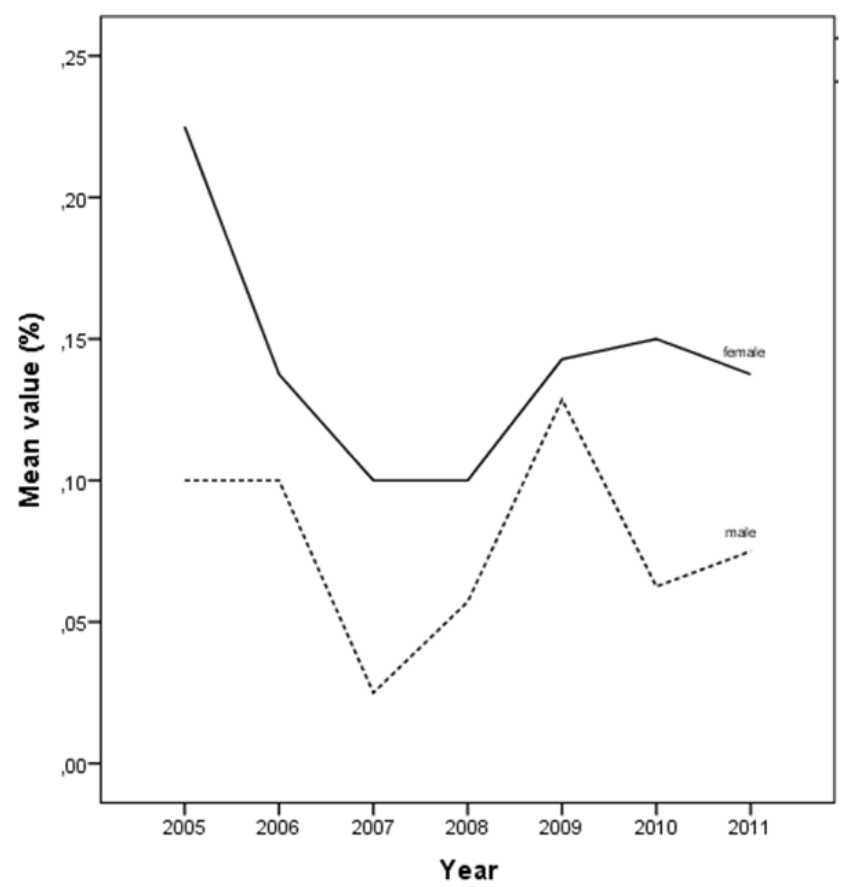

The overall percentages by country are shown in Table 3 . The highest mean value for delaying necessary healthcare due to distance was reported by females in Greece (0.44\%), but this value was not statistically significant compared to that of males $(p=.383)$. The lowest value for females was $0.07 \%$ and was found in France, Ireland, and the United Kingdom.

Overall, there was a minor gender gap in accessibility regarding distance. The mean values were typically lower for males; however the difference was only statistically significant in Ireland $(p=.026)$, where no males reported unmet medical needs due to distance to healthcare.

Table 3. Difference in the mean value between genders for the percentages of patients with unmet medical needs due to distance from 2005 to 2011 in eight European countries

\begin{tabular}{lllll}
\hline \multirow{2}{*}{ Country } & \multicolumn{2}{c}{ Mean value (\%) } & & Mann-Whitney $\boldsymbol{U}$ test \\
\cline { 2 - 3 } & Female & Male & \\
\hline France & 0.07 & 0.02 & .101 \\
Germany & 0.17 & 0.06 & $.017^{*}$ \\
Greece & 0.44 & 0.34 & .383 \\
Ireland & 0.07 & 0.00 & $.026^{*}$ \\
Italy & 0.10 & 0.07 & .383 \\
Portugal & 0.09 & 0.07 & .628 \\
Spain & 0.10 & 0.03 & .165 \\
United Kingdom & 0.07 & 0.03 & .209 \\
\hline
\end{tabular}

Note. Source: Calculations by the authors based on 2013 EUROSTAT data. ${ }^{*} p$ value $<.05$

\subsection{Effects related to unmet medical needs due to high cost}

Regarding healthcare accessibility constraints due to high cost, we calculated mean values of $2.53 \%$ and $1.80 \%$ for females and males, respectively from 2005 to 2011. We observed large increases for both genders in 2006, but these decreased until 2008, after which point increases were again noted. The gender gap persisted throughout the entire study period (see Figure 2). 
Figure 2. Percentages of male and female patients who reported unmet medical needs due to high cost in eight European countries from 2005 to 2011.

Note. Source: Calculations by the authors based on 2013 EUROSTAT data.

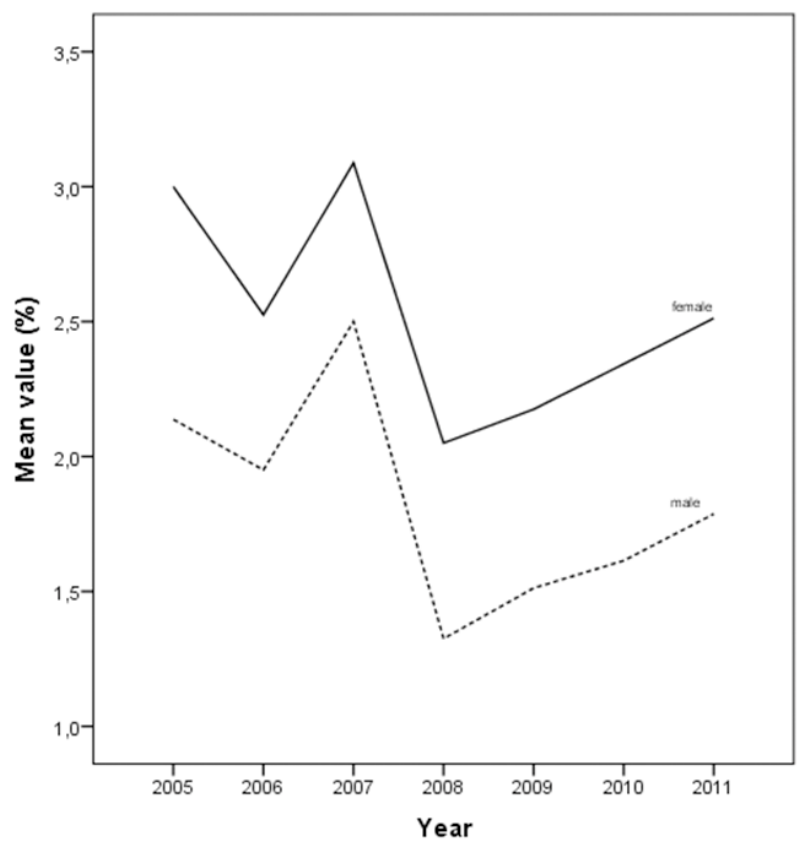

In the part of the population with unmet medical needs due to high cost, we found that the highest mean value was in females in Greece (5.17\%), Italy (4.39\%), and Portugal (3.80\%). However, regarding these countries, the gender differences were only statistically significant for Greece $(p=.007)$ and Italy $(p=.004)$ (see Table 4$)$.

Statistically significant differences in mean values related to a gender gap were also found for France (1.80\% female vs. $1.23 \%$ male, $p=.007)$ and Ireland (1.53\% female vs. $1.13 \%$ male, $p=.011)$. There was no gender gap due to healthcare cost for Germany, Portugal, Spain or the United Kingdom.

Table 4. Difference in mean values between genders for the percentages of patients with unmet medical needs due to high cost from 2005 to 2011 in eight European countries

\begin{tabular}{|c|c|c|c|}
\hline \multirow{2}{*}{ Country } & \multicolumn{2}{|c|}{ Mean value (\%) } & \multirow{2}{*}{$\begin{array}{l}\text { Mann-Whitney U test } \\
p \text { Value }\end{array}$} \\
\hline & Female & Male & \\
\hline France & 1.80 & 1.23 & $.007^{*}$ \\
\hline Germany & 2.89 & 2.60 & .902 \\
\hline Greece & 5.17 & 3.59 & $.007^{*}$ \\
\hline Ireland & 1.53 & 1.13 & $.011^{*}$ \\
\hline Italy & 4.39 & 2.99 & $.004^{*}$ \\
\hline Portugal & 3.80 & 2.70 & .318 \\
\hline Spain & 0.26 & 0.16 & .259 \\
\hline United Kingdom & 0.07 & 0.04 & .534 \\
\hline
\end{tabular}

Note. Source: Calculations by the authors based on 2013 EUROSTAT data. ${ }^{*} p<.05$

\subsection{Effects related to unmet medical needs due to waiting lists}

In general, there was a marked decrease related to waiting lists for both females and males from 2005 to 2011 , but a gap still exists with an average of $0.79 \%$ of females reporting associated accessibility constraints compared to $0.66 \%$ of males. Between 2008 and 2009, we observed a growing trend for both males and females, however, it remained higher for females. A decrease was observed for both genders from 2009 to 2010, which seemed to persist into 2011 for females but not males (see Figure 3). 
Figure 3. Percentages of male and female patients reporting unmet medical needs due to waiting lists in eight European countries from 2005 to 2011.

Note. Source: Calculations by the authors based on 2013 EUROSTAT data.

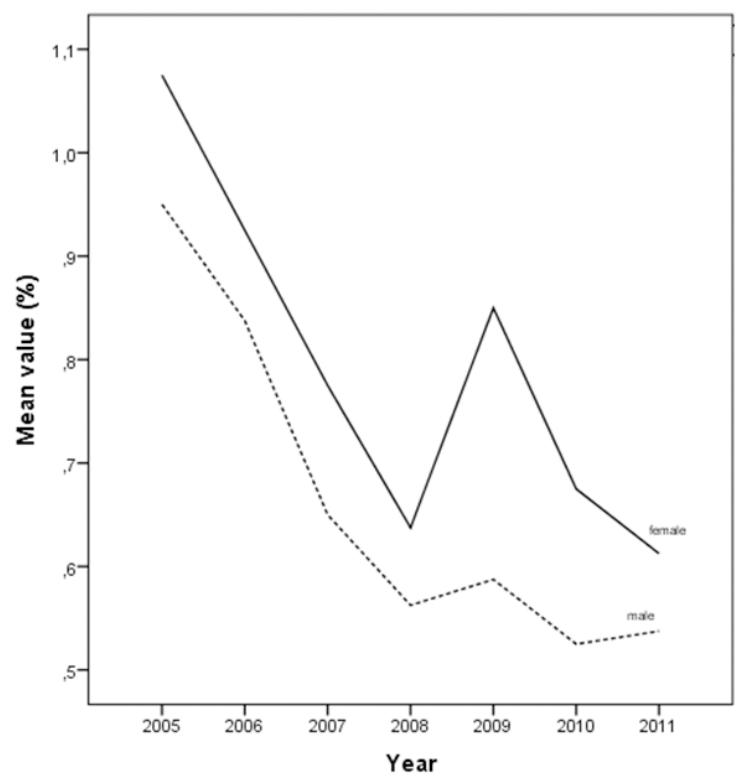

The values in Table 5 provide information about the minor relevance of waiting lists related to gender healthcare accessibility constraints. The highest mean value of $1.40 \%$ for females was in the United Kingdom, and the lowest was in France, where only $0.24 \%$ of females reported healthcare accessibility constraints related to waiting lists. Only data from Ireland provided evidence of a statistically significant gender gap in accessibility due to waiting lists. A mean value of $0.80 \%$ of females reported such constraints, compared to $0.53 \%$ of males ( $p=.017$ ).

Table 5. Difference in mean values between genders for the percentages of patients with unmet medical needs due to waiting lists from 2005 to 2011 in eight European countries

\begin{tabular}{lllll}
\hline \multirow{2}{*}{ Country } & \multicolumn{2}{c}{ Mean value (\%) } & & Mann-Whitney $\boldsymbol{U}$ test \\
\cline { 2 - 3 } & Female & Male & & \multicolumn{1}{c}{ value } \\
\hline France & 0.24 & 0.23 & .805 \\
Germany & 0.79 & 0.73 & .318 \\
Greece & 0.91 & 0.76 & .209 \\
Ireland & 0.80 & 0.53 & $.017^{*}$ \\
Italy & 1.37 & 1.19 & .053 \\
Portugal & 0.57 & 0.44 & .535 \\
Spain & 0.26 & 0.20 & .383 \\
United Kingdom & 1.40 & 1.24 & .383 \\
\hline
\end{tabular}

Note. Source: Calculations by the authors based on 2013 EUROSTAT data. ${ }^{*} p .05$

\section{Discussion}

Accessibility to the healthcare system is complex and is mainly based on structural, organisational and patient characteristics. It is identified on the European Social Chart as one of the main principles, which "emphasises the importance of transparent criteria for access to medical treatment and the obligation for States to have an adequate healthcare system which does not exclude parts of the population from receiving healthcare services. (...)A commonly used indicator is the variance across the EU in the percentage of residents reporting difficulties in accessing medical care for reasons related to the accessibility of health systems: waiting time, traveling distance and cost sharing”" ${ }^{26]}$.

In the present study, we considered three factors related to patient accessibility (distance, cost, and waiting lists) and assessed whether they were affected by gender. We observed gender-related trend patterns that were higher for females 
than for males for all three factors. In addition, the data indicate that the recent global financial crisis reinforced these inequalities.

We found that the major accessibility constraint was healthcare cost, and there was a statistically significant gender gap. The highest percentage of reported unmet medical needs related to cost was $5.17 \%$ for females in Greece compared to $3.59 \%$ of males. Among the countries in the sample, Greece has the highest number of physicians per 1,000 inhabitants and one of the lowest numbers of consultations of a medical doctor per inhabitant.

In Italy, 4.39\% and 2.99\% of females and males, respectively, report accessibility constraints related to overly expensive healthcare. That country had the opposite situation, with just 3.98 physicians per 1,000 inhabitants but 6.1 consultations by a medical doctor per inhabitant per year.

Italy and Greece have public healthcare systems mainly financed by taxes, and their healthcare budgets depend on the economic performance of the country. However, this factor is also affected by the unemployment rate, especially during an austerity period, which can dramatically decrease female income. As shown in Table 2, we found that female unemployment was higher than for males in both Greece (14.84\% vs. $7.69 \%)$ and Italy $(9.13 \%$ vs. $6.29 \%)$, which could explain our findings. For example, the country with the third highest percentage of unmet medical needs due to cost was Portugal; however a gender gap was not found, possibly due to the equal unemployment rates for both genders.

In the last years of the first decade of the 21st century, Portugal, Ireland, and Greece were receiving international bailout funds to provide financial support during a period of economic and financial turmoil characterised by high unemployment rates. The downturn required a redistribution of national budgets to respond to an overall decrease in public expenditure and an increase in social security demand. In addition, taxes related to healthcare have increased, mainly due to a general constraint on expenses. As such, healthcare may require additional financing and new mechanisms to regulate access.

As expected, the average household wage dropped, mainly due to the rising unemployment rate. The demand for healthcare could have been constrained due to individuals avoiding seeking care for minor episodes. Unfortunately, we were not able to compare acute and chronic healthcare demands or assess care depending on disease severity. Both of those factors could shed light on why there were unmet medical needs in these eight countries, but such data are not collected by Eurostat.

Nonetheless, experience from Spain shows that countries with a high percentage of free health services have populations that are unaware of the associated costs ${ }^{[27]}$, which may lead to unnecessary healthcare and deplete scarce healthcare resources, but there is no gender gap. In fact, Spain had one of the lowest figures related to unmet medical needs due to high cost; the number of consultations with a medical doctor per Spaniard was 7.65 per year, which was the second highest in the sample.

Regarding the distance to the healthcare and waiting lists, the percentages of the patients with unmet medical needs were dramatically lower than the mean percentage for cost. We consider that the gender gaps observed for Germany and Ireland related to the distance and for Ireland related to waiting lists are less critical than gaps related to cost. Nonetheless, the figures were justified as Ireland has the lowest numbers of physicians and medical consultations among the countries in the sample.

It seems that accessibility gender gaps are found in countries regardless of healthcare system type, and this phenomenon could also be explained by variables other than those studied here. Socioeconomic variables may be the most important, and future studies should assess whether gender gaps are largest in more deprived populations.

The implementation of effective social protection mechanisms should be considered to overcome accessibility constraints ${ }^{[28]}$ as there is growing evidence that negative impacts on health can be ameliorated by investment in social protection (...) in addition to healthcare provisions ${ }^{[29]}$. 
The current results highlight the need to design ongoing interventions related to different types of accessibility, which is the first step required to obtain healthcare. In order to be equitable and effective, these interventions must be gendersensitive. The use of gender-tiered incentives shared among health and social security is the preferred instrument to foster gender-related equity regarding healthcare accessibility.

\section{Conclusions}

We found a gender gap related to healthcare accessibility, mainly affecting females in Greece, France, Ireland and Italy. This was mainly due to expensive care, especially during the years of the financial crisis.

The gender gap can also be associated with poor socioeconomic conditions, regardless of the country or its healthcare model. A tiered intervention shared between health and social security is a preferred model to overcome this constraint.

Accessibility must be recognized as an integrative device ${ }^{[1]}$ as it is instrumental in achieving well being and societal productivity. A multifactorial evidence-based planning process should be promoted that characterises the underlying healthcare system and socioeconomic variables with a focus on gender constraints.

The full achievement of public health must rely on broad incentives to cope with a tiered concept of gender-related healthcare accessibility.

\section{Competing interests}

The authors declare that they have no competing interests.

\section{References}

[1] Wendt C. Mapping European healthcare systems: a comparative analysis of financing, service provision and access to healthcare. Journal of European Social Policy. 2009; 19(5): 432-445. http://dx.doi.org/10.1177/0958928709344247

[2] Levesque JF, Harris MF, Russell G. Patient-centred access to health care: conceptualizing access at the interface of health systems and populations. International Journal for Equity in Health. 2013; 12: 18. PMid: 23496984. http://dx.doi.org/10.1186/1475-9276-12-18

[3] Paéz A, Scott DM, Morency C. Measuring accessibility: positive and normative implementations of various accessibility indicators. Journal of Transport Geography. 2012; 25: 141-153. http://dx.doi.org/10.1016/j.jtrangeo.2012.03.016

[4] Wagner AK, Graves AJ, Fan Z, Walker S, Zhang F, Ross-Degnan D. Need for and access to health care and medicines: are there gender inequities? PLoS ONE. 2013; 8(3): e57228. http://dx.doi.org/10.1371/journalpone0057228.

[5] Merzel C. Gender differences in health care access indicators in an urban, low income community. American Journal of Public Health. 2000; 90(6): 909-916. PMid: 10846508. http://dx.doi.org/10.2105/AJPH.90.6.909

[6] Marmor T, Wendt C. Conceptual frameworks for comparing healthcare politics and policy. Health Policy. 2012; 107: 11-20. PMid: 22763200. http://dx.doi.org/10.1016/j.healthpol.2012.06.003

[7] Watanabe R, Hashimoto H. Horizontal inequity in healthcare access under the universal coverage in Japan; 1986-2007. Social Science \& Medicine. 2012; 75: 1372-1378. PMid: 22809794. http://dx.doi.org/10.1016/j.socscimed.2012.06.006

[8] Reeves A, McKee M, Basu S, Stuckler D. The political economy of austerity and healthcare: cross-national analysis of expenditure changes in 27 European nations 1995-2011. Health Policy. 2014; 115(1): 1-8. PMid: 24315493. http://dx.doi.org/10.1016/j.healthpol.2013.11.008

[9] Kringos DS, Boerma WGW, Zee J, Groenewegen PP. Political, cultural and economic foundations of primary care in Europe. Social Science and Medicine. 2013; 99: 9-17. PMid: 24355465. http://dx.doi.org/10.1016/j.socscimed.2013.09.017

[10] Johar GV, Moreau P, Schwarz N. Gender typed advertisements and impression formation: the role of chronic accessibility. Journal of Consumer Psychology. 2003; 13(3): 220-229. http://dx.doi.org/10.1207/S15327663JCP1303_04

[11] Rouessé J. Access to health care and social inequality. Oncology. 2013; 15: 17-19. http://dx.doi.org/10.1007/s10269-012-2240-z

[12] Gao M, Yao Y. Gender gaps in access to health care in rural China. Economic Development and Cultural Change. 2006; 55(1): 87-107. http://dx.doi.org/10.1086/505720 
[13] Box TL, Olsen M, Oddone EZ, Keitz SA. Healthcare access and utilization by patients infected with human immunodeficiency virus: does gender matter? Journal of Women’s Health. 2003; 12(4): 391-397. PMid: 12804346. http://dx.doi.org/10.1089/154099903765448907

[14] Tapp C, Milloy MJ, Kerr T, Zhang R, Guillemi S, Hogg RS, et al. Female gender predicts lower access and adherence to antiretroviral therapy in a setting of free healthcare. BMC Infectious Diseases. 2011; 11: 86. PMid: 21466704. http://dx.doi.org/10.1186/1471-2334-11-86

[15] Washington DL, Bean-Mayberry B, Riopelle D, Yano EM. Access to Care for Women Veterans: Delayed Healthcare and Unmet Need. Journal of Internal Medicine. 2011; 26(Suppl 2): 655-661.

[16] Godden S, Pollock AM. Waiting list and waiting time statistics in Britain: A critical review. Public Health. 2009 ; $123: 47-51$. PMid: 19054534. http://dx.doi.org/10.1016/j.puhe.2008.06.005

[17] Rotstein DL, Alter DA. Where does the waiting list begin? A short review of the dynamics and organization of modern waiting lists. Social Science and Medicine. 2006; 62: 3157-3160. PMid: 16377045. http://dx.doi.org/10.1016/j.socscimed.2005.11.030

[18] Street A, Duckett S. Are waiting lists inevitable? Health Policy. 1996; 36: 1-15. http://dx.doi.org/10.1016/0168-8510(95)00790-3

[19] Commission. Eurostat Database. 2013 [cited 2013 Nov 25]; Available from: http://epp.eurostat.ec.europa.eu/portal/page/portal/statistics/themes

[20] Wendt C, Mischke M, Pfeifer M, Reibling N. Confidence in receiving medical care when seriously ill: a seven country comparison of the impact of cost barriers. Health Expectations. 2011; 15: 212-224. PMid: 21631654. http://dx.doi.org/10.1111/j.1369-7625.2011.00677.x

[21] Weaver KE, Rowland JH, Bellizzi KM, Aziz NM. Forgoing medical care because of cost. Cancer. 2010; 116: 3493-3504. PMid: 20549763. http://dx.doi.org/10.1002/cncr.25209

[22] Pande AH, Ross-Degnan D, Zaslavsky AM, Salomon JA. American Journal of Preventive Medicine. 2011; 41(1): 1-8. PMid: 21665057. http://dx.doi.org/10.1016/j.amepre.2011.03.010

[23] Brown S, Castelli M, Hunter DJ, et al. How might healthcare systems influence speed of cancer diagnosis: A narrative review. Social Science and Medicine. 2014; 116: 56-63. PMid: 24980792. http://dx.doi.org/10.1016/j.socscimed.2014.06.030

[24] Garcia-Subirats I, Vargas I, Mogollón-Pérez AS, De Paepe P, Silva MRF, Unger JP, et al. Barriers in access to healthcare in countries with different health systems. Social Science \& Medicine. 2014; 106: 204-213. PMid: 24576647. http://dx.doi.org/10.1016/j.socscimed.2014.01.054

[25] Astell-Burt T, Flowerdew R, Boyle PJ, Dillon JF. Does geographic access to primary healthcare influence the detection of hepatitis C? Social Science \& Medicine. 2011; 72: 1472-1481. PMid: 21481509. http://dx.doi.org/10.1016/j.socscimed.2011.02.015

[26] Commission. Brussels, 4.4.2014. COM (2014) 215 final. Communication from the Commission. On effective, accessible and resilient health systems. Available from: http://ec.europa.eu/health/healthcare/docs/com2014_215_final_en.pdf

[27] Peiró M, Barrubés J. New context and old challenges in the healthcare system. Revista Espanola de Cardiologia. 2012; 65 (7): 651-655. PMid: 22633113. http://dx.doi.org/10.1016/j.recesp.2012.02.019

[28] Karanikolos M, Mladovsky P, Cylus J, Thomson S, Basu S, Stuckler D, et al. Financial crisis, austerity, and health in Europe. Lancet. 2013; 381: 1323-1331. http://dx.doi.org/10.1016/S0140-6736(13)60102-6

[29] Quaglio G, Karapiperis T, Van Woensel L, Arnold E, McDaid D. Austerity and health in Europe. Health Policy. 2013 ; $113: 13-19$. PMid: 24176290. http://dx.doi.org/10.1016/j.healthpol.2013.09.005 